\title{
FORTALECIMIENTO DE LAS INSTITUCIONES JUDICIALES CON EL PROPÓSITO DE ERRADICAR LA VIOLENCIA DE LA SOCIEDAD
}

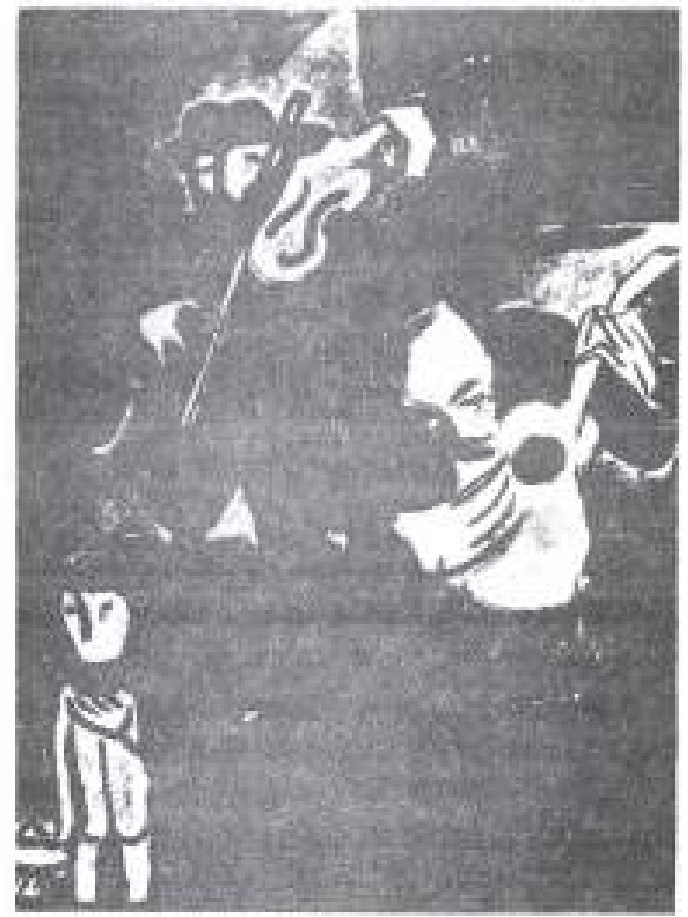

\section{DR. KIMBERLY THACHUK}

El Grupo INPAX de la Vicerrectoria de Investigación y Proyección Universituria de la Lnéversidad Autónoma de Manizales continata con la publicación de trafucciones de articulos que ticnen que ver con el problema de la violencia que se vive en todo el mundo en la actusalidad.

Traducción: J, OSXAR LLANO I.

Director, Departumento de Idiomass Extranjercos

Universbdad Autónoma de Manizales

\section{A NTECEDENTES}

El uso de la violencia ha constituido durante mucho tiempo el método mediante el cual numerosas sociedades han resuelto sus disputas. Sin embargo, el recurso de la violencia sólo tiende a eagendrar más violencia. Los valores democráticos y la observancia de los derechos humanos son incapaces de promoverse y sostenerse dentro de una atmósfera de desorden y de actos retributivos. En realidad, mientras que en muchos estados se realizan elecciones libres y limpias, se presenta el interrogante si estas constituyen credenciales suficientes para denominarlos como países con demo- 
cracias liberales. Se formula lo anterior en vista de que ante la ausencia de un orden social pacifi$c o$, los elementos esenciales de una democracia liberal, igualdad y libertad, no pueden ser ejercidos por los ciudadanos. Además, si el gobiemo no se halla limitado en su capacidad para ejecutar estas políticas mediante la constitución y mediante el poder de la ley y, como tal, es responsable de sus acciones, entonces su capacidad para ejercer su autoridad, especialmente frente a la crisis social, se ve severamente debilitada.

Dicho de otra manera, los gobiernos que carecen de la voluntad politica requerida, de la autoridad institucional y del poder organizado para mantener el orden. proteger los derechos humanos y procurar el bienestar socio-económico a sus ciudadanos, no solamente son deficientes, sino que más bien hacen que el estado sea incapaz de estar clasificado dentro de una verdadera democracia liberal - hayan sido o no elegidos mediante elecciones libres y limpias. Generalmente se ha acordado que la inestabilidad y la violencia resuitan de la pérdida que el estado experimenta del monopolio de su fuerza fisica legitima, de la incapacidad de realizar reformas sociales a través de canales legales, de la corrupción, con proporciones epidémicas. que se presenta en muchas entidades oficiales y de la prevalencia de organizaciones y actividades "para-estatales". Por consiguiente, en lugar de operar como debería, es decir, ejerciendo su poder coercitivo para mantener el orden, el estado puede multiplicar los factores de violencia contra su propia voluntad.

La vioiencia constituye generalmente una expresión de muchos fenómenos complejos política y socialmente entrelazados. Podemos considerar aquí la rivalidad partidista, el bandolerismo político, los levantamientos campesinos, el bandolerismo y la "justicia" estatal y pari-estatal o cualquier combinación de los anteriores. En realidad, la violencia puede tender a denotar un fenómeno específico, algunas veces convirtiéndose en el agente históri- co que reemplaza, de manera brutal, los métodos pacíficos que permiten transformar una sociedad. La violencia, o la amenaza o el uso de la fuerza física utilizados para hacerte daño a alguien o para intimidar o privar a otros de sus derechos ha sido usada indiscriminadamente en numerosos paises. con propósitos políticos, sociales o económicos. Factores tales como el cambio social ripido, la pobreza generalizada y las altas tasas de desempleo. que han fortalecido sus propias tasas de criminalidad altas, incluyen también en la actuaficad el incremento meteórico del crimen organizado.

Además, muchos sistemas políticos ostentan una tradición de ser menos que democráticos. Los odios partidistas que se han vivido en los filtimos sigios en muchos países generalmente carecian de una dirección central, aunque algunas veces eran promovidos por los funcionarios oficiales o por politicos con el propósito de intimidar la oposición. Estas acciones frecuentemente se convertian en oleadas de vioiencia sin sentido y representaban un paso retrogresivo significativo en el proceso de desarrollo social. La mayoría de las luchas que se presentaron en las áreas rurales de muchos paises respecto a la reforma y al balance socio-económico de las tierras dejaron un legado que facilita la generación de nuevos niveles de actividad violenta. Esto ha generado en la gente una concepción axiológica baja respecto a la vida humana y con una inclinación a recurrir a la violencia, más que a la conciliación, como el primer argumento a esgrimir en caso de presentarse un conflicto.

\section{-54. Unviersidad Altónoma de Manizales}


Esta inclinación hacia ta violencia ha llevado a muchas administraciones a situarse en posiciones dificiles en lo concerniente al diseño de poíticas judiciales equitativas y factibies. La identificación de la existencia de un problema y la necesidad de solucionarlo constituyen solamente una parte de la lucha que se ha de entablar para lograr una reforma. El gobierno puede convertirse en garante de las estabilidad de las expectativas humanas en todo cuanto sea posible. Cuando un gobiemo está trabajando bien, el proceso político resuelve el conflicto de manera continua y discreta. No obstante, cuando un gobierno es incapaz de mantener el orden social y consumar la legitimidad, la democracia es virtualmente imposible $y$ el sistema gubernamental comienza a fracturarse a lo largo de líneas personales of familiares, en donde las personas o los partidos se enfrascan en una lucha por la posición y el control sobre los recursos cada vez más escasos.

Los esfuerzos verdaderos tendientes a lograr un sistema judicial se ven, por consiguiente, nublados frecuentemente por afitiaciones partidistas en las áreas de influencia de la vida politica del país las cuales abundan en conjunción con sistemas inamovibles de relaciones patrón-cliente y de intereses creados. Desafortunadamente, tal ambiente constituye un imán que atrae los traficantes del poder privado. Se presume que es mucho más fácil operar un sistema ilegal o prescindir de un sistema en donde falta el orden y en donde las instituciones se hallan minadas por el clientelismo y por la corrupción. Una vez se ha presentado el rompimiento del institucionalismo, los eslabones que quedan de la cadena de mando se dedican a la extorsión y al soborno.

Cuando los instrumentos de coerción quedan en manos de grupos no gubernamentales, las comunidades se ven sujetas a la acción de intereses atin más arbitrarios y personalmente motivados. En al gunas regiones, muchos grupos, incluyendo grupos insurgentes y carteles de drogas, frecuentemente proveen "servicios públicos" tales como alojamiento, educación y aún "justicia" a los ciudadanos. lo cual significa que han reemplazado virtualmente el estado y la autoridad legítimamente constituida. No obstante, por muy magnánimas que puedan parecer estas acciones, el hecho es que estos líderes auto-nombrados no fueron elegidos democráticamente por el pueblo. Más bien, se insinuaron ellos mismos utilizando grandes cantidades de dinero y continuan operando con relativa impunidad como los señores de los latifundios feudales, con la ley de la "jungla" como la guia para la provisión de su bondad y de su justicia.

Por consiguiente, mientras que los ciudadanos que viven en estas regiones se hallan sujetos a una constituciōn justa y bien estructurada a nivel formal, a nivel informal se hallan sujetos a muchas reglas atbitrarias tal como existen en cualquier estado autoritario. La carencia de libertad y el temor por la seguridad personal que son las caracteristicas de un gobierno autoritario conducen a lo mismo, sólo que la coerción se emplea más por los grupos que por el gobierno. En consecuencia, es algo oneroso hablar acerca del tipo de sistema de gobierno que tiene un pais o de cómo su sistema judicial debe ser reformado cuando el gobierno no tiene el monopolio exclusivo del uso del poder. A pesar de este problema, se pueden realizar muchos cambios en lo concerniente a la reforma de las instituciones judiciales de tal manera que funcionen efectiva y eficientemente con el propósito de restaurar la paz. el orden y el buen gobierno para la sociedad. 


\section{CUÁL DEBE SER ENTONCES EL PAPEL DE LAS INSTITUCIONES JUDICIALES?}

Cuando se trata de reformar las instituciones judiciales es importante reconocer que ellas son sólo partes de todo un sistema. Es decir, estas instituciones no están solas $y$, por consiguiente, no son independientes de los efectos de otros componentes que también pertenecen al sistema de justicia. Ellas, por consiguiente, no pueden emprender actividades con el propossito de reformar sus propias practicas. Este es especialmente el caso cuando se presenta la corrupción al interior de una entidad judicial especifica. En consecuencia, se requiere una cierta forma de administración conjunta para establecer los objetivos comunes y para situar, de manera efectiva, los recursos cuando éstos escasean y la criminalidad aumenta.

Un primer paso importante al revisar si las instituciones encargadas de administrar justicia están logrando una aplicación adecuada de la justicia consiste en determinar si están evitando la aplicación

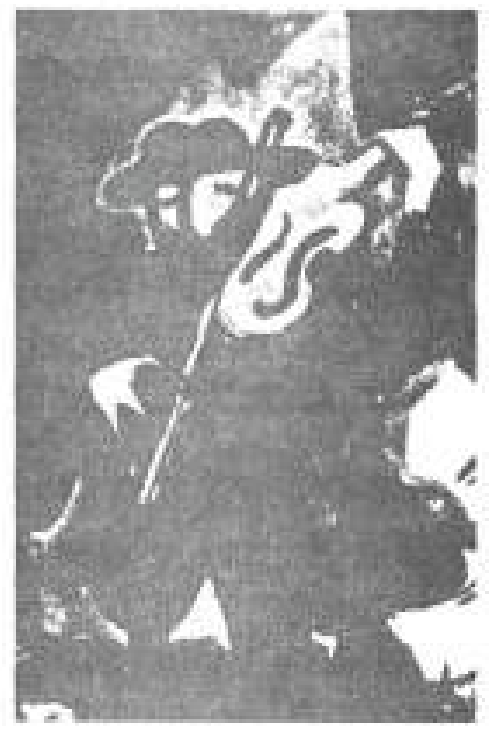

.56. Uhuversidad Aưónoma de Manizales arbitraria del poder grupal o personal. Las cortes deben estar en capacidad de decidir, de manera imparcial. los casos que se les asignan y no deben estar sujetas al control o a la influencia indebida por parte de la rama ejecutiva del gobierno. De igual manera, no se debe destinar la policia para determinar o para defender propósitos que se hallen por fuera de su mandato legal como tampoco debe estar encadenada a limitaciones impropias en sus actividades de investigación y arresto de personas sospechosas de violar la ley. Los programas correccionales, de igual manera, no deben ser utilizados para encarcelar o controlar las personas a quienes no se les ha encontrado culpables de haber transgredido la ley o quienes se hallan confinadas injustamente por cualquier razón. En consecuencia, no basta establecer y reformar un sistema de justicia, sino que también se debe controlar las personas encargadas de controlar y vigilar ef funcionamiento del sistema. Uno de los retos más deletéreos que se presenta en este caso es la prevalencia de la corrupción, la cual degrada el sistema de justicia de muchas maneras y no permite que éste funcione eficientemente dentro de los confines de la ley.

Un hecho muy importante entre las consideraciones existentes para establecer y mantener funcionando de manera efectiva un sistema de justicia penal es la conciencia de que el requisito fundamental es el de proteger el público y de controlar el comportamiento inadecuado, de una parte, mientras, que de otra parte, se asegura la libertad individual y los derechos del infractor. Por consiguiente, no son solamente la corrupción y la violencia las que socavan el sistema de justicia penal en muchos países, sino también una variedad de factores, muchos de los cuales son exógenos a la estructura y objetivos de la sociedad como un todo. Muchos de estos objetivos entran en conflicto unos con otros y se prestan a contradicciones en lo concerniente al sistema de justicia penal. En realidad, se ha enfatizado que el éxito de un sistema de justicia depende en gran parte de los métodos que 
emplea la sociedad para lograr los objetivos de control social y de si estos métodos son compatibles unos con otros (Duffee et al., 1978: 5099).

Parece que en muchos paises varias estrategias se hallan en conflicto unas con otras, especialmente en lo referente a la disuasión y a la retribución. Mientras que la necesidad de la disuasión ha aumentado en muchas jurisdicciones desde la década de los setenta, la demanda de retribución, sin embargo, ha sido relativamente débil. Esto se puede explicar mediante el hecho que la retribución involucra la búsqueda activa y el castigo de aquellos que infringen la ley. Los agentes de violencia y del crimen quienes deben ser castigados son tan efectivos en la intimidación y en el soborno a los miembros del sisterna judicial que el temor a la violencia como también la prevalencia del personal corrupto tiende a alejar los esfuerzos del sistema respecto a la retribución y a acercarse de una manera retórica a la búsqueda de la disuasión. Irónicamente, debido a los extremos de violencia y de corrupción que socavan la capacidad del estado para enjuiciar a los criminales, un sistema que busca descubrir las instancias y los agentes de la actividad criminal tiene la posibilidad de continuar siendo débil - quizás solamente instigando más violencia. En consecuencia, un sistema que continúa enfatizando en la disuasión contribuirá a que el sistema de justicia criminal se vuelva más sofisticado, En otras palabras, un pian estructural que altere los resultados de los actos criminales, en lugar de enfocarse en los criminales mismos se verá menos influenciado por grupos criminales especificos. De otras parte, los entes de justicia deberán verse influenciados, de manera creciente, por grupos de toma de decisiones de alto nivel y por grupos de expertos. Obviamente, todas las formas de criminalidad no pueden ser predecidas en detalle, y en consecuencia, las limitaciones constitucionales que pesan sobre el sistema deben asumirse como cambios sociales.

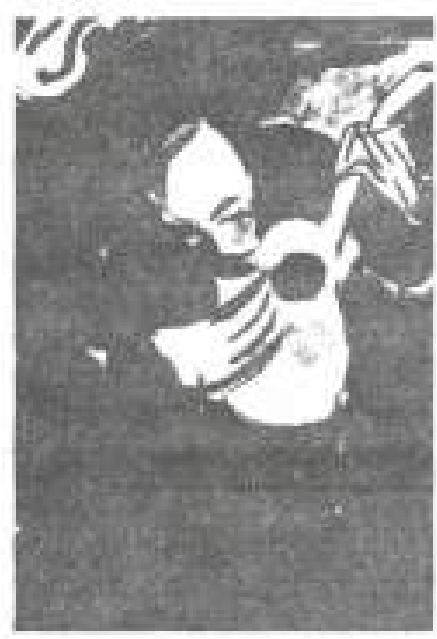

En realidad, la implementación de técnicas retributivas, cuando han sido empleadas rigurosamente, han conducido frecuentemente a los fenómenos de escuadrones de la muerte militares y paramilitares, los cuales realizan actos de violencia extrema. Las décadas de 1970 y 1980 fueron testigos de cómo muchos gobiernos, de manera creciente, acudian al uso de la fuerza y de técnicas represivas ejecutadas más de manera no oficial que oficial. Las técnicas represivas reflejan aquelias técnicas empleadas por las organizaciones criminales e incluyen las amenazas anónimas, los secuestros, las desapariciones, los asesinatos selectivos y las masacres colectivas. Claramente, en aquellos países en donde es manifiesta la inclinación hacia la violencia, la búsqueda de un sistema de justicia altamente dependiente de la retribución conducirá solamente al resquebrajamiento de la democracia, por ejemplo, no diferente al periodo vivido en la Argentina bajo el régimen de las Juntas durante tres décadas.

De acuerdo con lo anterior, se le debe dar una consideración extrema a la preservación de la ley. Este compromiso engendra una variedad de consecuencias. La primera es que las violaciones a la ley 
deben ser castigadas, pero dicho castigo debe es. tar dentro de lo considerado por la ley. Es decir, las politicas antiterroristas de las democracias liberales no deben comprender represalias contra segmentos de la población de los cuales se sospecha simpatizan con quienes están al margen de la ley. Por consiguiente, si los gobiemos democráticos reaccionan contra la violencia utilizando la fuerza de manera indiscriminada contra ciertos segmentos de la población, no están recurriendo a las mismas prácticas de los terroristas, sino que están construyendo, más que debilitando, cuaiquier clase de apoyo que el grupo al margen de la ley pueda tener entre los miembros de la población. Las declaraciones de la ley marcial y de las medidas de emergencia, por consiguiente, no tienden a fortalecer la lucha contra la violencia. De igual manera, las fuerzas de seguridad y las unidades militares o de policia, dadas sus funciones de combatir la violencia, deben ser monitoreadas estre. chamente para asegurar que operan dentro del esquema de la ley. Esto quiere decir que se debe mantener el control civil en todas sus actividades a través de la vigilancia legislativa y de las limitaciones judiciales.

Existen al menos dos factores que contribuyen a centrar la atención en el propósito social de las diferentes instituciones pertenecientes al sistema de justicia penal y en las politicas relacionadas con

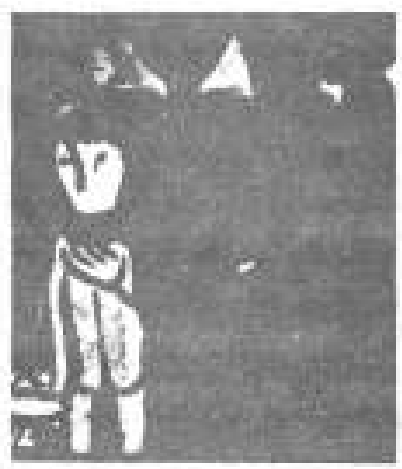

dicho sistema. El primero consiste en mejorar la eficiencia y la efectividad de la justicia penal en términos generales, tratando de ver los programas de "justicia penal" como un "sistema" que puede ser administrado empleando los principios y las prácticas en conjunción con cualquier empresa corporada. Esto requiere de numerosos refinamientos de las prácticas de los administradores dentro de las instituciones de justicia penal, incluyendo e incrementando el deseo, $5 i$ no el requisito, de articular, para la consideración pública, las diferentes estrategias o enfoques que se han empleado en las organizaciones. Con respecto a estos cambios debe presentarse una "apertura" creciente del gobiemo en lo referente a proclamar el trabajo en el sistema de justicia penal y someterlo a la auditoría y revisión externas. A medida que los estados se democratizan, esta tendencia se vería estimulada parcialmente por una demanda creciente, por parte de la ciudadania, de la responsabilidad en el gobierno. La articulación creciente de los derechos ligados a la adquisición de información respecto a las cuestiones públicas $\mathrm{y}$ a la participación pública en cambios de políticas relacionados con los programas sociales hará que los gobiernos tomen una actitud más "educativa" en sus acciones. La participación de un público informado servirá solamente para fortalecer las instituciones de justicia penal otorgándoles credibilidad y legitimidad.

Las instituciones oficiales se ven frecuentemente acompañadas de mucha frustración, confusión e incertidumbre. Con frecuencia, un cambio en el enfoque de la responsabilidad jurisdiccional requiere una reevaluación de las estructuras administrativas y de gestión, to cual determina tanto la política como la praxis. Existen tres áreas que requieren atención especial; en primer lugar, las ini- 
ciativas de reforma se hallan sujetas con mucha frecuencia a dificultades procedimentales que surgen de la ruptura o del conflicto entre jurisdicciones. En este caso, el éxito de la iniciativa de reforma se halla severamente obstaculizado y se hace necesario que la autoridad legislativa se encargue de dichas escisiones. En el segundo caso el problema de costo-efectividad ha determinado que las funciones $y$ las jurisdicciones que se sobreponen sean dinamizadas y que la duplicación de esfuerzos sea tomada en consideración en el momento de emprender una reforma. En muchos casos la división de la responsabilidad genera una "lucha" sobre los escasos recursos de tal manera que se presenta la entropia institucional. Este problema. mas no la corrupción por si misma, genera una dificultad seria de mala administración de los recursos escasos a través de la duplicación, la sobreposición de funciones, la falta de comunicación. la ineficiencia, la inefectividad y la carencia de una base racional para la continuidad de muchas organizaciones. Finalmente, se le debe prestar atención a la organización de las entidades judiciales de tal manera que éstas logren la compatibilidad máxima con las estructuras de autoridad que proveen otros servicios de justicia. Los objetivos de cada entidad deben ser consistentes con y apoyar los objetivos y metas de otras entidades que se hallan también al interior del sistema judicial.

Por consiguiente, un elemento de importancia capital al efectuar la reforma de entidades judiciales es el requisito consistente en revisar los objetivos a largo plazo con el propósito de evaluar las implicaciones de estos factores. La reforma debe ser administrada de manera eficiente, efectiva y consistente. Esto requiere que las filosofias operantes en las entidades judiciales y las estrategias resultantes deban ser revisadas consistentemente.

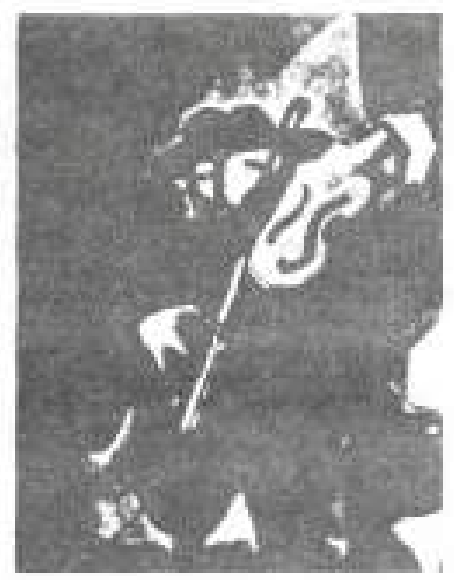

También es necesario que cada entidad se organice de tal manera que asegure la integridad administrativa a través de líneas claras de autoridad, en donde la responsabilidad para administrar la reforma sea considerada como una actividad inherente asociada a los objetivos y estrategias del sistema de justicia penal como un todo.

Es importante especificar que el juicio referente a si una reforma debe efectuarse o no depende en gran parte de las perspectivas ideológicas, teóricas y politicas de las personas encargadas de asegurar la gobemabilidad. Cualquier evaluación de las iniciativas de reforma dentro de las entidades públicas es efectiva cuando dicha reforma se toma en términos tanto de proceso como de resultado. Con frecuencia es difícil establecer objetivos firmes y consistentes ya que el sistema de justicia penal constituye una reflexión de los movimientos y cambios en las actitudes sociales, las "perspectivas profesionales ${ }^{+1}$ y las creencias politicas. Por consiguiente, un peligro inherente al realizar una reforma es el hecho que frecuentemente se convierte en un método mediante el cual se retiene algo a la fuz de dichos movimientos y cambios o se convierte en un movimiento hacia algo que ratifica los valores politicos, sociales, culturales u organizacionales básicos, no obstante se puedan presentar otros cambios de actitud y de creencias. 
Estos valores básicos incluyen aspectos tales como el ejercicio administrativo de los recursos públi$\cos$ (costo-efectividad y costo-eficiencia), el evitar el castigo cruel e poco frecuente (tratamiento humanitario), el mantenimiento $\mathrm{y}$ la promoción del respeto por la ley (igualdad en la aplicación de la misma) y el derecho que tienen los ciudadanos, en una sociedad democrática y libre, a determinar los parámetros dentro de los cuales el estado puede realizar sus intervenciones - incluyendo la condición que el estado debe ser responsable de sus ciudadanos en lo referente a dichas intervenciones dentro de dichos paraimetros.

\section{CONSIDERACIONES ETICAS}

Al formular y alterar una politica pública dentro del ámbito de la justicia penal es necesario considerar como pueden ser revisados y considerados en la práctica los principios o los valores (ética). Se debe encontrar el equilibrio entre los valores sociales, especialmente en lo referente a los dere. chos del individuo versus aquellos de la colectividad. En este aspecto, la noción del contrato moral. el cual considera la aplicación de los valores y principios morales en el dominio del servicio público. constituye el tema central. En dondequiera que grupos de personas vivan en comunidad y particularmente cuando ellos mismos se organizan políticamente dentro de unas fronteras bien definidas, articulan filosofias y principios como en una constitución y poseen una ciudadanía que puede ser identificada de alguna manera, entonces la interacción existente entre todas estas personas, particularmente entre los ciudadanos corrientes y las personas elegidas o seleccionadas para gobernarlos. se presenta la idea del contrato moral. Dicho contrato refleja ciertas expectativas que se hallan por fuera del contexto de una ley positiva. pero que en cierta manera dirigen la política social, y puede ser considerado como fa manera mediante la cual los partidos políticos se presentan ellos mismos al electorado a través de sus plataformas y proyectos respecto a las políticas propuestas, Estas políticas generalmente se presentan de tal manera que tratan de preservar la fe dentro del entendimiento de lo que acepta el publico, al igual que como el entendimiento de fos límites de la tolerancia pública. En consecuencia, cuando el público responde negativamente a las actividades de los servidores públicos, por cjemplo, cuando un jefe de gobierno hace uso de su investidura oficial para obtener un beneficio personal, se debe a que tales acciones se considera como violaciones del contrato moral. El contrato moral tiene que ver con las expectativas respecto a los límites dentro de los cuales cualquier entidad gubernamentai debe operar.

Cuáles son los límites del contrato moral respecto a las instituciones que constituyen el sistema de justicia penal? Qué tan lejos puede llegar el estado al confinar, castigar o investigar personas antes que se haya violado o transgredido el contrato moral? Esta constituye una consideración ética importante cuando se trata de fortalecer las instituciones

*La articulación creciente de los derechos ligados a la adquisición de información respecto a las cuestiones públicas y a la participación pública en cambios de politicas relacionados con los programas sociales hará que los gobiernos tomen una actitud más "educativa" en sus acciones.» 


\title{
*Cualquier evaluación de las iniciativas de reforma dentro de las entidades públicas es efectiva cuando dicha reforma se toma en
}

\author{
términos tanto de proceso como de resultado.»
}

judiciales. Lo es de manera muy particular desde el punto de vista de hacer el trabajo del gobiemo y especialmente, cuando dicho trabajo tiene que ver con la criminalidad y el mantenimiento del orden social. Generalmente, se espera que el contrato moral requiera credibilidad respecto a las limitaciones impuestas por la ley y las demás regulaciones. Se supone, además, que los servidores públicos no pueden infringir la ley y deben ser fieles al contrato moral. Con base en lo anterior, el contrato moral existe como un instrumento conservador del control social. Dicho contrato trata de conservar y preservar el orden pacifico al proteger los intereses de todas las personas en sus interacciones unas con otras. En consecuencia no se permite que nada llegue a los extremos. Se supone que la comprensión de la justicia implicita en el contrato moral mantiene la interacción entre los gobernantes y los gobernados dentro de parámetros razonables.

La ley no provee, por sí misma, los elementos prácticos del contrato moral. Este contrato se refleja parcialmente en la ley y en la filosofía social y en las políticas públicas. Los códigos específicos de ética emergen fuern de este ambiente. Los códigos de ética no constituyen necesariamente parte de la ley positiva sino más bien que son afimaciones de expectativas profesionales. Cuando un profesional se ve comprometido en el control de actividades o con comportamiento intrusivo con otras personas, actúa de tal manera de acuerdo con su entendimiento de la ética, el cual se formula frecuentemente en un código escrito. Ya que los codigos de ética son conservadores en su tono, gene- ralmente identifican los parámetros de conducta dentro de los cuales se estructura la responsabilidad y se dirimen los conflictos.

La elaboración de estándares de práctica puede. por consiguiente, fortalecer el sistema de justicia penal y contribuir a definir los parámetros respecto al comportamiento aceptable de los empleados en estas organizaciones. Mientras que éstos no sean necesariamente reglas que limiten la capacidad de las personas para actuar a discreción, sirven como pautas para el comportamiento corporado, para los estándares de práctica profesional, para los códigos de conducta, para las reglas de procedimientos y para todos aquellos aspectos que reflejen consideraciones éticas.

Existen muchos factores que determina como se establecen estos estándares o códigos. Uno de ellos lo constituyen los acuerdos internacionales. Por ejemplo, las Naciones Unidas han desarroliado un conjunto de estándares para ei tratamiento de los transgresores una vez se hailen bajo la acción del sistema de justicia penal. Estas pautas han sido utilizadas en muchos paises como guias generales respecto a las condiciones que se deben observar en el cuidado y mantenimiento de dichos transgresores.

\section{CONCLUSION}

En su concepción más básica, el gobiemo existe con el propósito de mantener el orden a través del 
uso selectivo de la fuerza. Si esto no se puede lograr, entonces la ley, y por consiguiente, muchas formas de coerción, podrian ser tomadas en las manos de comerciantes privados del poder quienes son lo suficientemente inteligentes y poderosos para asumir el control de la situación. El resultado de la coerción ejercida por entidades diferentes a las gubernamentales constituye generalmente un rompimiento del orden. Dicho resultado, con mucha frecuencia, se demuestra por la actitud de desdeño completo respecto a todas las operaciones gubernamentales y respecto a su capacidad para saltisfacer los requerimientos básicos tales como el mantenimiento del orden en la sociedad. En un intento por restaurar la legitimidad, los gobiemos han recurrido, de manera errónea, al empleo de la coerción de manera creciente con el propósito de re. ganar el control social, El mantenimicnto y el fortalecimiento de la autondad y la integridad de las instituciones judiciales son hechos esenciales para cvitar esta situación. La autoridad de las instituciones judiciales debe generar respeto tanto de manera simbólica como en la práctica. Si las instituciones tienen una fundamentación de apoyo solida, pueden asegunr el respeto que necesitan por parte del püblico para asf luchar contra el crimen. El público otorgara la libertad de justicia para logrario sin la necesidad sentida de la critica y la sospecha continuas. Por consiguiente, en los paises en donde existe la preocupación por el funcionamiento de las entidades judiciales, requieren también de la confianza para atender las percepciones tanto simbolicas como operacionales, Si el público percibe que las instituciones se han tornado maís efectivas y eficientes, entonces se logran resultados verdaderos tanto operacionales como simbólicos. En consecuencia, si las instituciones judiciales determinan sus valores sociales subyacentes y se ve claramente que dichos valores se adhieren a sus operaciones habituales, entonces se generarí el respeto por la integridad $y$ la autoridad.

\section{BIBLIOGRAFIA}

Exsiedt, John, 1991, "Camakian Crime Potiey", C.T. Griffiths eds.

Dror, Yebeckel. 1986, Foolicy Making Under Advernity. Prentice Hall Ine.

Forester, John. 1499, Patuang in the Face $\alpha$. Power, Univensty of Californa Press.

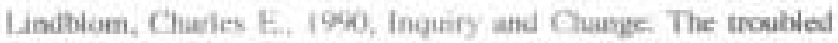
Atlenge to Underitand and Shape Society; Yale Univeraily Press.

Pal, 1.5, 1992. Puhlis Palicy Analysis, 2-i Ed. Tomntex Neison.

Rosentery. Tina, 1991, Children of Cain: Vixilence and the Viokent in Latin Americi, Wiltiam Momow and Compony.

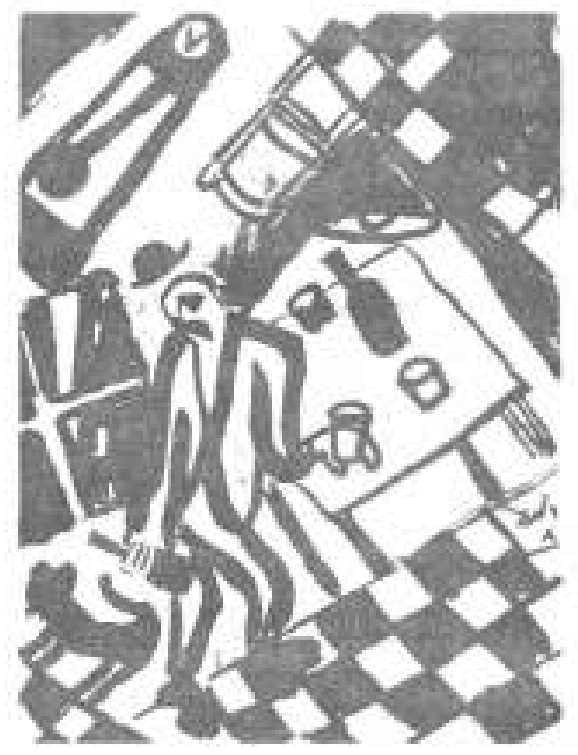

